Revista Iberoamericana. Vol. LXVI, Núm. 191, Abril-Junio 2000, 309-324

\title{
LITERATURA JUDÍA LATINOAMERICANA: MODELOS PARA ARMAR
}

\author{
POR \\ FLORINDA F. GOLDBERG \\ Universidad Hebrea de Jerusalén \\ Universidad de Tel Aviv
}

La producción de escritores judíos de América Latina ha suscitado, desde sus comienzos a principios del siglo XX, la cuestión de si la misma constituye o no un espacio diferenciado, dentro de la literatura latinoamericana y dentro de la literatura judía. Las diversas respuestas están obviamente ligadas a los contextos históricos y culturales tanto de las obras como de los planteos teóricos. Me propongo revisar algunos de los modelos enunciados y añadir una propuesta a este debate permanente.

Comenzaré por un planteo muy poco conocido y bastante sorprendente por las circunstancias de su enunciación. En 1925, en una revista norteamericana de cultura judía llamada The Menorah Journal, ${ }^{1}$ apareció un artículo de Isaac Goldberg titulado "Jewish Writers in South America”. Isaac Goldberg (1887-1938), lecturer de literatura hispanoamericana en Harvard, había publicado Studies in Spanish-American Literature (1920) y Brasilian Literature (1922), así como traducciones de autores sudamericanos. En su artículo de 1925, comienza elogiando el Canto a la Argentina de Rubén Darío, tanto por su valor estético como por sus propuestas ideológicas: su "Pan-Americanism”, la visión de una América, "the northern and southern Americas as the huge plates of a continental balance", que se logrará mediante "a fraternal union of the "Anglo-Saxon race with Latin-America'”;'2 y en particular, la visión de Argentina como mother nation de todos los desarraigados y por tanto “a new Zion” para el inmigrante judío (I. Goldberg, “Jewish Writers” 473). ${ }^{3}$ A

\footnotetext{
${ }^{1}$ El Menorah Journal (1915-1962), publicado en Harvard por la Intercollegiate Menorah Association, (antecesora del movimiento Hillel), era una revista de difusión intelectual destinada a promover el "humanismo judío" (según el modelo del "nuevo humanismo" de W. James y G. Santayana) y a conformar una identidad judía laica basada en la noción de que la Diáspora sería superada por el nacionalismo cultural judío (y no mediante el proyecto sionista). Su cuidadosa presentación y la calidad de sus textos debían otorgar al judaísmo una ubicación honorable dentro del campo intelectual norteamericano. Constituyó durante varias décadas un importante espacio de debate del judaísmo estadounidense, si bien perdió prominencia tras la Segunda Guerra Mundial (véase Grumet, "The Apprenticeship of Lionel Trilling” 153-163 y Encyclopaedia Judaica, XI-1371).

2 "¡Gloria a América prepotente! / Su alto destino se siente / por la continental balanza / que tiene por fiel el istmo: / los dos platos del continente”; "ímpetu exterior hermana / a la raza anglo-sajona / con la latino-americana” (Darío, “Canto a la Argentina” 928, 929).

${ }^{3}$ Las referencias a los inmigrantes judíos y a la Argentina como "nueva Sión” — suerte de altisonante versión de Gerchunoff- figuran en Darío (“Canto a la Argentina” 908, 916 y 933).
} 
continuación, el autor traza un panorama — sin duda totalmente novedoso para sus lectores- de las “voces” judías sudamericanas que constituyen, según él, “a slender sound in the continental chorus" (474), y señala la existencia, no de una influencia judía (como sería, da a entender, el caso de los Estados Unidos), sino de "Jewish influences in the cultural life of southern America” (474, énfasis del original) que pueden prefigurar "a really Jewish contribution” (475) en la región. Tras comentar la vida y obras de António José da Silva ‘O Judeu', Jorge Isaacs y Abraham López-Penha y mencionar el origen judío de Guillermo Valencia, Goldberg se concentra en lo que ocurre en Buenos Aires, donde "Jewish youth [...] has begun a movement of consciously Jewish influence upon the milieu” (480). Sus conocimientos sobre periodismo, publicaciones e intereses intelectuales de la comunidad judía argentina, así como una breve referencia a la “aparición del antisemitismo en el país, se basan en su correspondencia con Samuel Glusberg, cuya narrativa le merece un comentario positivo y bastante extenso (en contraste con su breve referencia a Los gauchos judíos de Gerchunoff), en tanto, nuevamente, "the humble source” (481) de una futura creación literaria más importante.

La perspectiva desde la que Goldberg juzga y compara el presente y profetiza el futuro de la literatura escrita por judíos en Argentina y por extensión en "Sudamérica” es, por supuesto, la de los Estados Unidos:

Perhaps we have here the beginnings of a Spanish-Yiddish literature, comparable to the early days in our own country when Kobrin and Libin were discovering the soul of the immigrant and following his transformation in the new milieu (481).

Inmediatamente se corrige, indicando que Glusberg es más bien comparable con Abraham Cahan, debido a que ambos escriben "in the tongue of the nation” (481). Lo más interesante del artículo es el rol extraliterario — “extra-esthetic" — (480) que asigna a esta literatura judía en formación: constituir un instrumento de mediación y armonización entre las dos Américas,

a link between the northern and southern continents — a link forged of minds that by nature are universal in outlook and endowed with aspirations that trascend the grabbing fists of political mountbanks. "Hands across the sea" may have been a good slogan in its day. "Minds across the continents" I suggest as a better (483).

A esta conclusión arriba tras señalar varios factores: tanto el "universal outlook” (482, $483)^{4}$ de Glusberg como su oposición a "the anti-United States propaganda that is going on in South America” (482) —las menciones de Calibán y Ariel $(481,482)$ muestran que Goldberg ha leído a Rodó- lo convierten en un modelo del nuevo intelectual y escritor judío sudamericano que podrá no sólo crear una literatura de “esthetic values” (483), sino hacer realidad aquella articulación continental anunciada por Darío en el Canto a la Argentina.

${ }^{4}$ Es probable que esta idea del universalismo judío provenga del ensayo de Thornstein Veblen "The Intellectual Pre-eminence of Jews in Modern Europe", publicado en 1919 y de gran impacto entre los intelectuales judíos norteamericanos - y no sólo en ellos: Jorge Luis Borges lo menciona en "El escritor argentino y la tradición” (Discusión 160). 
Tras sus descripciones, evaluaciones y pronósticos subyacen dos nociones: la condescendiente y paternalista de que los judíos del sur — “down there”- (479) se beneficiarán de conocer e imitar a los del norte; y la suposición de que los países del sur habían de alcanzar una situación de pluralismo sociocultural en la que el judaísmo y los judíos desempeñarían un papel semejante a "the great part played in the North American intellectual world by Jewish minds” (483).

Si bien es lógico suponer que Glusberg leyó el artículo de Goldberg, no tengo información acerca de la difusión del mismo en América Latina. Algún eco de él resuena tal vez en un artículo de 1934 de Luis Karduner, "Misión del escritor judío en la literatura argentina”, en el que da por "evidente [...] que una gran parte de la joven intelectualidad judía está aportando su riqueza espiritual para constituir el tesoro de la cultura argentina, en formación” (145). Karduner invalida, sin embargo, a los escritores judíos que se dedican solamente a "los trillados motivos de carácter universal" (146) y afirma normativamente que su temática debe ser "las características sui-géneris de la vida del pueblo judío en América [Latina], que es diferente a la de [...] Polonia, Rusia, Estados Unidos, Alemania o Eretz Israel” (147), dando como ejemplos/modelos de esa "literatura costumbrista" (148) a I. Zangwill, M. Gold y J. Wasserman (148). Tres años después, en su acerba crítica a Pan criollo de César Tiempo, le reprochará (entre otras cosas) la utilización de estereotipos judíos que no responden a la peculiaridad del judío argentino (Karduner, “Carta abierta”).

Los optimistas pronósticos de Goldberg en cuanto a la homologación de los desarrollos culturales en el "sur” y el "norte” no se cumplieron en las décadas siguientes. Continuando con la Argentina, en las de 1930 y 1940 los escritores judíos sintieron la necesidad de incluir en sus creaciones una apologética que los salvaguardara del cargo de doble lealtad, afirmándola como una virtud: "Judío y argentino / con blasón de inmigrantes” (César Tiempo, Sabadomingo 32), “soy un patriota argentino y un defensor del judaísmo” (Lázaro Liacho, Sónidas 17).

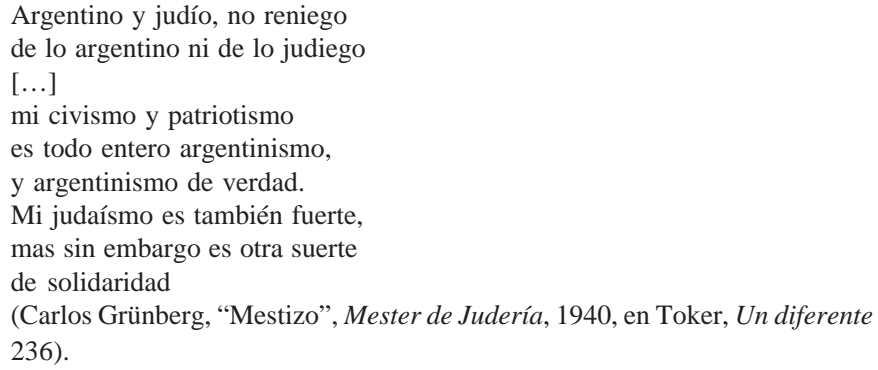

Apologética que también subyace a la rotunda afirmación de Borges en su prólogo a ese libro de Grünberg: “Grünberg, poeta, es inconfundiblemente argentino” (Toker, Un diferente 176; énfasis mío). Estos autores aspiraban a reunir armónicamente en sus textos lo universal, lo judío, lo nacional; en la práctica, su condición de judíos los limitaba en tanto argentinos. Naomi Lindstrom destaca cómo ciertos temas y sobre todo ciertas críticas de la 
realidad inmediata les estaban tácticamente vedados, debido al temor de suscitar "hostility by appearing unenthusiastic about the Argentinian Nation", lo que los colocaba en un "potentially paralyzing dilemma" (Lindstrom, Jewish Issues 1-2). ${ }^{5}$

Como lo insinuaba Karduner, en ese mismo período apareció también la conciencia (mejor dicho, el proyecto) de un fenómeno cultural de dirección inversa: el enriquecimiento de la cultura judía mediante la incorporación de lo latinoamericano. Ello resultó más urgente a medida que se evidenciaba la destrucción de la fuentes europeas del judaísmo durante la Segunda Guerra Mundial. Salomón Resnick, fundador y director de la revista Judaica (Buenos Aires, 1933-1946) indicó lo imprescindible de semejante proyecto, para el judaísmo general y el judaísmo americano: "es menester que el sector judío que se halla fuera del alcance del caos destructivo, aludimos con ello al judaísmo de América, ponga su mayor empeño en salvaguardar los valores culturales, y en proseguirlos dentro de lo posible, en esta tierra exenta de prejuicios raciales [...] Para que la futura cultura judía de América tenga su expresión propia, su modalidad particular y su valor esencial, deberá aportar a la cultura judía este aspecto americano que existe de hecho y que sólo hace falta investigar y ahondar" (Resnick, "Florecimiento" 242). ${ }^{6}$

A partir de mediados del siglo, un creciente número de escritores judíos latinoamericanos han venido enfocando en sus textos, alternativa o simultáneamente, temas judíos, latinoamericanos y universales. Pero más importante que su cantidad es su creciente visibilización y su busca de una definición de pertenencia literaria que no sea ni aislacionista ni apologética. Esa voluntad de visibilización, particularmente notable en los años ochenta y comienzos de los noventa, generó una conciencia de grupo y la tendencia de los escritores a reunirse y debatir una problemática percibida como común. Ello, por otra parte, se inscribía en un contexto de fenómenos concurrentes: el creciente interés por los estudios del judaísmo latinoamericano en las ciencias históricas y sociales; ${ }^{7}$ y el desarrollo de un importante movimiento crítico y de investigación de sus creaciones como espacio diferenciado dentro de la literatura latinoamericana en general y/o las literaturas nacionales. A ello se sumó la investigación de temas judíos en autores no judíos, que implica una legitimación de lo judaico como formante de la cultura latinoamericana. ${ }^{8}$

Mencionemos algunos hitos de este proceso de auto-visibilización. En 1983 aparece el libro de Leonardo Senkman La identidad judía en la literatura argentina, cuyo doble propósito es:

\footnotetext{
${ }_{5}$ Véanse los capítulos sobre estos autores en Senkman (La identidad judía) y Lindstrom (Jewish Issues) y F. Goldberg (“The Complex Roses” 74-79).

${ }^{6}$ Véase Lindstrom ("Las polémicas culturales en las páginas literarias de Judaica").

${ }^{7}$ Prueba del mismo son, además de una extensa bibliografía, la creación de espacios académicos como la Sección Latinoamericana del Instituto de Judaísmo Contemporáneo de la Universidad Hebrea de Jerusalén (1967),y la de asociaciones de investigadores como LAJSA (Latin American Jewish Studies Association, Estados Unidos, 1982), que ha realizado hasta 1999 diez congresos internacionales, y AMILAT (Asociación de Investigadores del Judaísmo Latinoamericano, Israel, 1974), la cual tiene a su cargo desde 1984 la Sección Latinoamericana del cuatrienal Congreso Mundial de Estudios Judaicos.

${ }^{8}$ En este aspecto, Borges fue el autor favorito: véanse Sosnowski (Borges y), Aizenberg (The Aleph), Alazraki (Borges and).
} 
legitimar [...] el estudio de la realidad nacional a partir de los escritores de origen migratorio [...] y también [...] comprobar qué le ha pasado a su identidad judía una vez que ellos se acrisolaron, conforme las pautas culturales, cívicas y nacionales de la sociedad argentina (11).

Entre 1984 y 1992 se realizaron en Israel varios “Congresos de Escritores Judíos de América Latina”, promovidos por el Instituto de Intercambio Cultural Israel-Iberoamérica, España y Portugal. En 1985, dentro del Congreso Mundial de Estudios Judaicos tuvo lugar una mesa redonda organizada por AMILAT sobre creación literaria judía en Latinoamérica y en Israel, en la que Saúl Sosnowski sostuvo que, por una parte, “[e]scribir desde una pertenencia nacional y étnica [...] comienza a constituir una respuesta literaria a los dilemas de integración y un corte tajante frente a la renuncia final que es la asimilación” (Sosnowski, La orilla inminente 160); por la otra, esa escritura contribuye a los debates centrales: "[a]l incidir en la literatura latinoamericana global, se asienta insistentemente en la visión que niega la homogeneidad del continente proyectando así su rechazo de toda fórmula fácil” (165). ${ }^{9}$ En 1986 se realizó en Buenos Aires el "Primer diálogo en torno a lo judío en la literatura argentina y latinoamericana”, cuyas ponencias y debates se publicaron ese mismo año con el título (ciertamente programático) de Pluralismo e identidad: Lo judío en la literatura latinoamericana. En ese año se crean la Asociación Internacional de Escritores Judíos en Lengua Hispana y Portuguesa y su revista Noaj. ${ }^{10}$ En 1987 Sosnowski publica La orilla inminente. Escritores judíos argentinos. La producción de libros y artículos críticos fue y continúa siendo abundante. En los años siguientes (y bajo la égida del doble quincentenario en 1992) se realizaron en el continente y en Israel encuentros dedicados a la creación literaria judeo-latinoamericana y a la temática e influencia judías en la literatura latinoamericana, así como secciones literarias permanentes en los congresos de LAJSA y el World Congress of Jewish Studies; varios de ellos dieron lugar a publicaciones. ${ }^{11}$

Vale la pena mencionar, por contraste, dos propuestas extremas que en esos años negaron la existencia misma del fenómeno en discusión. Una fue planteada por el sociólogo y escritor argentino Joseph Hodara (y discutida por quien esto escribe) en una mesa redonda

\footnotetext{
${ }^{9}$ El texto de Sosnowski apareció en Punto de Vista VII-25 (1985): 17-19, y constituye el cap. V de La orilla inminente de donde lo citamos.

${ }^{10}$ Ambas con sede en Jerusalén. Noaj ha publicado hasta la fecha 13 números. Los miembros de la Asociación, los colaboradores asiduos de la revista y los autores estudiados en sus páginas constituyen un listado de los principales involucrados en los debates de los ochenta y noventa: M. Aguinis, E. Aizenberg, I. Blaisten, L. Barr, A. Bortnik, A. Brailovsky, I. Chocrón, H. Costantini, A. Dujovne Ortiz, R. Feierstein, M. Fingueret, E. Friedler, L. Futoransky, A. Gelbtrunk, G. Gervitz, M. Glantz, N. Glickman, F. Goldberg, I. Goldemberg, J. Goldenberg, M. Goloboff, R. Halac, R. Igel, S. Kovadloff, E. Lerner, A. Liberman, N. Lindstrom, M. Moscona, A. Muñiz, J. Najenson, S. Pecar, T. Porzecanski, M. Satz, M. Scliar, E. Seligson, L. Senkman, S. Sosnowski, A.M. Shua, A. Steinberg, M. Szichman, A. Szpunberg, C. Teitelbaum, E. Toker, D. Viñas, I. Viñas, E. Wechsler, H. Yánover y otros.

11 Entre ellas: Sosnowski et al. 1985; Ensayos sobre judaísmo latinoamericano, "Actas del V Congreso Internacional” ("Literatura”); Finzi, Toker y Faerman (El imaginario judío en la literatura de América Latina-visión y realidad); Rosa (500 años); AMILAT Noaj, Actas del V encuentro y "Quinto centenario".
} 
realizada en Jerusalén en 1987, con motivo de la aparición de Noaj. Hodara, pese a ser miembro de la redacción de la revista, sostuvo la imposibilidad de hablar de "escritores judíos latinoamericanos” debido a la discontinuidad cultural e idiomática entre éstos y la tradición judaica. En cambio, sí hallaba semejante continuidad en los novelistas judíos norteamericanos.

La otra posición extrema (y complementaria en cierto modo) fue enunciada por el escritor judío francés Bernard-Henri Lévy en ese mismo año. Lévy no se refirió al caso latinoamericano sino a los escritores judíos en general, negando su pertenencia nacional en nombre de su universalidad:

Los escritores judíos están destinados a la soledad y al cosmopolitismo, más que otros escritores. Se abstienen más que otros de todo lo que pueda parecer una pertenencia colectiva exclusiva a un país. Se resisten a las "raíces", al "inconsciente colectivo", al "espíritu del pueblo". En una palabra, a todo lo que sea "comunidad”. (Lévy, "Existe-til une literrature juve?” 12)

Y, en una hiperbólica inversión de los términos (que recuerda no poco al ya citado ensayo de Veblen de 1919): "El gran escritor es siempre cosmopolita. En este sentido, todos los grandes escritores son también un poco judíos” (“The Intellectual”). Es casi innecesario aclarar que para la gran mayoría de los escritores judíos de América Latina las negaciones formuladas por Hodara y Lévy resultan igualmente inaceptables.

Recordemos qué tenían en común los protagonistas de los debates destinados a hallar anclaje a una identidad que se revelaba compleja y múltiple. Creadores y/o investigadores judíos nacidos y/o formados en América Latina, se sentían parte natural de las literaturas de sus países de origen y a través de ellas de la latinoamericana. ${ }^{12}$ En los años setenta muchos debieron emigrar por razones políticas y se establecieron en otros países sury norteamericanos, Europa e Israel. Aún para quienes no se habían ocupado antes en sus obras (o en su vida privada) del judaísmo, esa crisis constituyó un recordatorio de su origen judío en tanto “a tradition of multiple exiles and migrations” (Glickman, “Introduction” 9); en la acertada imagen de Senkman, "se vieron empuñando dos cayados en este inesperado éxodo, uno de los cuales les resultó angustiosamente familiar” (Senkman, "Exilio y literatura judía” 2). Los que se quedaron en su patria reaccionaron literariamente como los desterrados: el exilio real o simbólico constituyó un núcleo generador de su escritura. Como ya lo señalamos, el impulso a hallar un espacio de pertenencia acotado por su condición judía tomó especial vigor en un período posterior, hacia mediados de los ochenta, cuando la residencia en la patria original o en un país de elección ya se había vuelto una opción y no una compulsión.

El modelo de autoidentificación prevalente partía de la noción de mestizaje, generalizada entonces en los estudios sobre la cultura latinoamericana. Parecía natural que el mestizaje como signo identificador del continente incluyese también la combinación cultural y literaria con lo judío, lo cual además combatía la amenaza de la marginalidad al permitir

${ }^{12}$ Esta caracterización no excluye del grupo, por supuesto, a investigadores no judíos o no nacidos en América Latina. 
desplazar el acento de lo particular (lo judío) a lo general (el mestizaje). ${ }^{13}$ En palabras de Ricardo Feierstein:

\begin{abstract}
Este mestizaje aparece reflejado en temáticas, texturas de estilo y recursos del lenguaje, que buscan un punto de encuentro, una síntesis que permita reconciliar la doble afirmación: latinoamericana y judía. El reconocimiento de las distintas arterias y la lucha por no renunciar a ninguna, ya que todas forman parte de la vida cotidiana, constituyen el eje dramático en donde circula una cuestionada identidad. La reivindicación alegre y positiva de la judeidad transforma lo que era muda y torpe mutilación en descubrimiento de las raíces. La tierra americana, patria irrenunciable de la infancia o lugar de elección vital, es el otro pilar sobre el que se apoya la definición. Ni repliegue ciego sobre sí mismo ni asimilación... Ser iguales a los demás y, a la vez, ser diferentes (Feierstein, "Judíos latinoamericanos”, citado por Goldemberg, El gran libro de América 1088).
\end{abstract}

En su introducción a una selección de poetas judíos en español, escribió Santiago Kovadloff:

Son, en suma, las lenguas castellana y portuguesa las encargadas de articular [en América Latina] la enunciación de lo judío [...] Es así como se genera esa fecunda condición mestiza $[\ldots]$ que $[\ldots]$ enmarca con elocuencia una idiosincracia judía que, emparentada a otras por obvias razones, no es empero ninguna de ellas. El mestizaje aludido no es sino el entramado ya indisoluble de dos tradiciones originalmente diferenciadas como son la judía y la de América latina pero que, por obra del entrecruzamiento prodigioso de las circunstancias, terminaron conformando una nueva entidad (“En el umbral” 144).

¿Y en qué orden, en ese caso, colocar los adjetivos descriptivos de la pertenencia: “judío argentino”, “uruguayo judío”? Sosnowski aportó en su libro fundamental de 1987 (y en varios ensayos individuales), una respuesta dinámica que fue recibida en el debate como definición magistral. Se trata de la “teoría del guión”, según la cual lo definitorio en una denominación como “judeo-latinoamericano” (en el orden en que se quiera) está, antes que en los términos relacionados, en el "guión definitorio" (La orilla inminente 13) y "autorreferencial” (23) que pone en evidencia la articulación y el equilibrio (inestable y dialéctico) de "la unión de lo diferente": "En el Nuevo Mundo se ofrecen opciones claramente delineadas: ambos componentes, el judío y el nacional latinoamericano, están dados con atributos y conductas diferenciadas; también las combinaciones de ambos están sometidas a fluctuantes lealtades” (23). Por ende, “[e]l guión también señala la victoria de lo múltiple y compuesto contra la asimilación” (35). Al mismo tiempo, Sosnowski sostenía que, si bien

en los últimos años un respetable núcleo de autores jóvenes ha emergido como una notable y poderosa voz global [...] el conjunto de obras [...] no constituyen una categoría literaria separada [...] Estas obras pasarán a la historia como segmentos integrales de sus

\footnotetext{
${ }^{13}$ Me limito a mencionar la existencia de esa otra vuelta de tuerca que es el triple mestizaje de los escritores judíos latinoamericanos establecidos en Israel, situación que constituye a la vez un desexilio y un nuevo y diferente exilio. Véase Pecar ("El periplo de un escritor judeo-argentino").
} 
respectivas literaturas nacionales y no como una entidad separada con la etiqueta de "literatura judeo-latinoamericana”. Es el crítico quien extrae a estas obras de su ámbito nacional para montar un nuevo y vasto texto literario galardonado con un título colectivo (32-33, énfasis del original).

Mediante esta mirada crítica (que incluye también la del lector lego) “es factible, como lo hacemos, hablar de un sector judío de la literatura latinoamericana a partir de una aproximación temática de lo judío ante lo latinoamericano” (34). En otro momento, Sosnowski amplía su noción de "aproximación temática” a la de "motivo":

Cuando motivos que hasta ahora no habían sido utilizados son incorporados a un texto que - sea cual fuere su perspectiva - construye una interpretación literaria de la realidad, y cuando ese motivo tiene raíces en la tradición judía o en una interpretación de motivos judíos, podemos integrarlo legítimamente como un texto situado dentro de una tradición global que pertenece a esta categoría literaria (25-26).

El modelo propuesto por Sosnowski deja entonces abierta (o resuelve negativamente) la cuestión de si es posible insertar en el espacio de lo judeo(guión)latinoamericano a un autor de esa doble filiación que no tematice motivos judíos (Clarice Lispector es un caso prototípico $)^{14}$ o, lo que es aún más problemático, distribuir en diversas categorías a las obras de un mismo autor.

Queda entonces abierta la cuestión de un "estilo”, "visión de mundo” o "arquitectura anímica” judía (Rozitchner 79) que constituiría el sustrato profundo de una escritura que temáticamente no aluda a lo judío. En el congreso de 1986 Santiago Kovadloff dio una respuesta ambigua, en nombre de "los que escribimos y somos judíos": "No escribimos, necesariamente, como judíos; somos en cambio siempre judíos que escribimos” "Legitimar la diversidad cultural” 28). Teresa Porzecanski apostó por una definición vía “el pluralismo del discurso judío" contra "el fascismo del discurso absoluto": "la necesidad permanente de desdoblamiento de las estructuras del discurso, de bifucración, de ambigüedad, de reinterpretación permanente a partir del contraste con la posiblidad que queda fuera del discurso" ("Debate abierto" 150). Darrell Lockhart, en su reciente diccionario de escritores judíos latinoamericanos, explica el criterio que lo guió:

The question was should it include only those writers whose works directly reflect a Jewish identity while excluding those whose work do not [...] I arrived at the conclusion that the dictionary should in its totality be a critical sourcebook of Latin American Jewish writers and not just Jewish writing (Lockhart, Jewish Writers viii)

y luego propone, siguiendo a Irving Howe, la noción de

Judaic substance $[\ldots]$ that is, texts that contain Jewish metaphysical content, Kabbalism, a reliance on Hebraic hermeneutics, an emphasis on textual interpretation, Midrashic commentary, Talmudic exegesis, and the power of the written letter and word. This does

${ }^{14}$ Una aproximación a esta cuestión en B. Waldmann (en prensa). 
not mean that writers replicate these styles of writing, but that their literature draws on and is informed by these traditional Jewish modes of scriptural production and thought (xxiv, énfasis mío).

En la década del noventa, y con las limitaciones de una perspectiva no suficientemente distanciada, podemos señalar algunos fenómenos que se sumaron al juego de fuerzas que conforman el lugar y la (auto)identidad de los escritores judíos de América Latina. El primero es un desplazamiento geográfico del foco de la producción crítica: la mayor cantidad de investigaciones sobre el tema se realiza y publica en los Estados Unidos, donde el mismo se ha consolidado dentro de los estudios latinoamericanos (lo prueba este número de la Revista Iberoamericana) y en menor medida de los judaicos (ambos de enorme expansión académica en las últimas décadas), y en el programa de congresos latinoamericanistas generales (LASA, FIEALC, ICA, etc.); a las investigaciones críticas se sumó en los últimos años un notable incremento en las traducciones de obras unitarias y antologías. Entre éstas merece mencionarse una reciente, en castellano pero publicada precisamente en la encrucijada cultural de Puerto Rico, por el escritor peruano-norteamericano Isaac Goldemberg bajo el ambicioso título El Gran Libro de la América Judía (que por cierto evoca el proyecto de su “casi-tocayo” Isaac Goldberg en 1925 “Jewish Writers”). Lo más llamativo de este impresionante volumen de casi 1.200 páginas, organizado en trece “tratados” temáticos, es la supresión del nombre de los autores junto a cada texto; si bien las autorías son recuperables mediante el índice final, el libro procura "crear la ilusión de [una] voz colectiva” (El Gran Libro 18) que constituiría una respuesta adicional a las preguntas sobre la existencia o no de una "literatura judeo-latinoamericana". ${ }^{15}$

El segundo y muy importante fenómeno es que el escritor judío y el tema judío han recibido, en general, un alto grado de legitimación como parte integral de las culturas y literaturas nacionales. ${ }^{16}$ Ello parece haber disminuido y aún eliminado fricciones e incomodidades. Quizás sea consecuencia de esa normalización un tercer fenómeno: la casi desaparición de los encuentros de escritores dedicados al debate sobre su identidad, tema quizás ya resuelto o irrelevante.

Pese a la dilución del debate, quiero intentar una aproximación complementaria a la comprensión del escritor judío latinoamericano y su obra — descripción, y no definición. Creo que la noción del mestizaje es un modelo sólo parcial, si más no fuera porque en América Latina no todos los mestizajes han realizado el proyecto teórico, a saber, que el discurso mestizo que incluye el de una minoría fuertemente marcada ocupe un lugar central y no marginal en la cultura nacional y continental. El guión de Sosnowski, como él mismo

\footnotetext{
${ }^{15}$ Véanse las reseñas a la antología de Goldemberg en Muñiz-Huberman (“Reseña”) y F. Goldberg ("Reseña”).

${ }^{16}$ And yet, and yet... En la edición de 1968 de Los gauchos judíos por el Centro Editor de América Latina, la nota de contratapa informa que "Gerchunoff [...] emigró a muy temprana edad a la Argentina” y aclara que "Prácticamente todas sus experiencias vitales y, sin duda, toda su formación intelectual, son argentinas; también su producción de escritor pertenece, sin vacilaciones, a la historia de nuestras letras” (énfasis mío). ¿Qué dudas o vacilaciones podrían aquejar a la editorial progresista formada tras la intervención militar de la Editorial Universitaria de Buenos Aires en 1966?
} 
lo señalara, no une componentes fácilmente reconocidos como armónicos o aun del mismo prestigio cultural. ${ }^{17}$

Utilizaré aquí la fluctuación que, en otro contexto, señala Antonio Cornejo-Polar ${ }^{18}$ entre las “dos posiciones de enunciación” del migrante y del mestizo, que no constituyen una "dicotomía [...] sino [...] a veces pueden y deben articularse” ("Tradición migrante” 55). Frente a "la ideología salvífica del mestizaje, con su neoplatónica esperanza en la armonía de los contrarios [como] modelo ejemplar de las intersecciones transculturales" (46), dice Cornejo-Polar:

prefiero preguntarme - y sé que la respuesta será tentativa— si la condición migrante funciona — como sin duda sucede con la del mestizo — como un locus enunciativo [...] que podría remitir a la constitución de un sujeto disgregado, difuso y heterogéneo: el sujeto migrante (50) .

Este sujeto migrante “estratifica sus experiencias de vida y no puede ni quiere fundirlas porque su naturaleza discontinua pone énfasis precisamente en la múltiple diversidad de esos tiempos y de esos espacios y en los valores y defectividades de los unos y los otros" (49).

Su conclusión es que, en el caso de Arguedas, ambos discursos efectivamente se articulan porque poseen mucho en común:

en uno y otro caso se trata de la producción de discursos encabalgados en varias culturas, conciencias e historias [...] Subrayo en este orden de cosas la dinámica centrífuga del discurso migrante y su reivindicación de la múltiple vigencia del aquí y el allá y del ahora y el ayer (51, énfasis mío). ${ }^{19}$

Creo que es posible señalar la presencia de una conjunción dinámica entre los discursos del mestizo y del migrante en la obra de los escritores judeo-latinoamericanos. Esa conjunción se juega en el "maravilloso espacio" de la escritura mencionado por Moacyr

17 Véase, sobre todo, Sosnowski (La orilla inminente 17-18 y 28-29). Solotaroff aplica la misma imagen con el mismo sentido a los escritores judeo-norteamericanos: "marginality had the implication of standing apart, as the American-Jewish writer was perceived to do with respect to both sides of the hyphen" (“American-Jewish" 37).

${ }^{18}$ Se trata de su ponencia en el "III Encuentro Latinoamericano en Berkeley" (1994).

19 "Migrant literature is individual, subjective, diverse; it reflects but also may exaggerate or even invert the social experience that drives it. We may be surprised, and hence illuminated, by the migrant's feel for the quotidian and commonplace, and by migrant perceptions of the odd and the exotic (...) The migrant's voice tells us what it is like to feel a stranger and yet at home, to live simultaneously inside and outside one's immediate situation, to be permanently on the run, to think of returning but to realize at the same time the impossibility of doing so, since the past is not only another country but also another time, out of the present. It tells of long-distance journeys and relocation, of losses, changes, conflicts, powerlessness, and of infinite sadnesses that severely test the migrant's emotional resolve. It tells of new visions and experiences of the familiar and unfamiliar. For those that come from elsewhere, and cannot go back, perhaps writing becomes a place to live" (King, Cornell y White, Writing Across Worlds, XV). 
Scliar: "Is it difficult to belong to two worlds? Yes. But then, between these two worlds lies a wonderful space for the writer", precisamente en la dialéctica que él mismo establece entre "to belong" y "between" (Glickman, "Introduction II" 29). En la misma interviene, obviamente, su origen migratorio (vivido personalmente o recibido como relato familiar), así como la (frecuente) experiencia migratoria/exiliar en carne propia. Antes dije que también en autores "sedentarios" aparece lo migratorio como núcleo productivo de la escritura; añado que, por otra parte, el escritor emigrado y el escritor exiliado, pese a fuertes diferencias emocionales y valorativas en sus experiencias, comparten su forma de relacionarse con aspectos fundamentales de su trabajo como el lenguaje, el contexto vital, la temática y el público.

El escritor judío latinoamericano tematiza las experiencias migratorias propias o ajenas, individuales o familiares, reales o imaginadas, presentándolas a menudo como una otredad, una diferencia, que constituyen un obstáculo entre el personaje/el narrador y su integración al medio en que vive. El mestizaje es entrevisto como una meta anhelada pero quizás esencialmente utópica. No en vano tituló Sosnowski a su libro La orilla inminente; esa orilla no ha sido alcanzada todavía, aunque se haya nacido en Argentina o cualquier otro país latinoamericano.

Es sabido que la más difundida metáfora de la pertenencia es la "raíz”, el “arraigo”. Como tal aparece en el poema "Carta de naturalización” de Myriam Moscona (Las visitantes). ${ }^{20}$

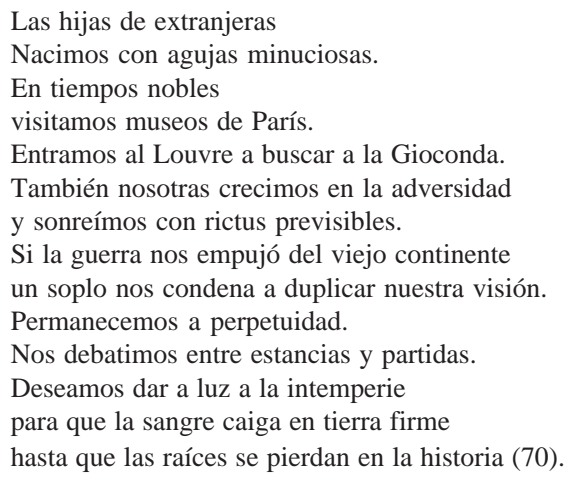

En los últimos versos, el tiempo verbal del “deseo” no realizado, el proyecto aún utópico de la "naturalización”, es naturalmente el subjuntivo: “caiga”, "se pierdan”. Algo muy diferente, por ejemplo, de los dos rotundos "soy" complementarios enunciados por otro "hijo de inmigrantes”, Astor Piazzola, en el tango que dedica a la memoria de su padre, “Adiós, Nonino":

\footnotetext{
${ }^{20}$ En un trabajo en vías de publicación, analizo el interesante cambio de título sufrido por este poema, que en su primera versión se llamó "Solicitud de naturalización” (F. Goldberg, "“Carta de naturalización’”).
} 


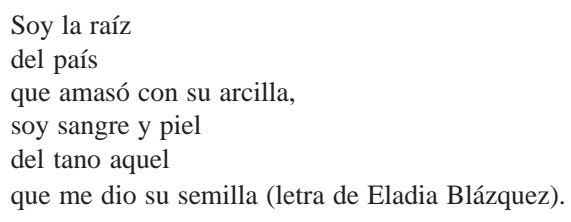

Pero el proyecto de Moscona es menos simple de lo que parece a primera lectura. Si bien la "tierra firme” parece sugerir la patria concreta donde se ha nacido, la "historia" del último verso puede ser más que una historia. En muchos textos judeo-latinoamericanos se escribe el deseo de recuperar toda aquella otra historia que sólo se conoce por referencia, por relatos familiares, por fotografías, por indagaciones históricas: ${ }^{21}$ no sólo registrar una nostalgia arqueológica por lo que no se ha tenido ni conocido directamente sino, paradójicamente, procurar incorporarlo a la propia vida y al propio cuerpo - o escribir la frustración ante la imposibilidad de esa recuperación. La autenticidad consiste, entonces, en la pertenencia, más propia del migrante que del mestizo según Cornejo-Polar, a dos espacios, dos historias, dos idiomas. Y si esa duplicidad acarrea la marginalidad de lo diferente, esa marginalidad es reivindicada como una ambigua forma de la "completud".

Jacobo Glantz, inmigrante establecido en México, afirma:

$$
\begin{aligned}
& \text {...sigo } \\
& \text { pidiendo una visa } \\
& \text { para cualquier puerto } \\
& \text { (Glantz 148). }
\end{aligned}
$$

Eliahu Toker, nunca exilado ni emigrado, escribe:

$$
\begin{aligned}
& \text { En realidad, sin haber estado allí nunca, } \\
& \text { aún no dejé el Hotel de Inmigrantes } \\
& \text { ni llegué a Buenos Aires todavía } \\
& \text { (“Buenos Aires”, Mamá, Papá y otras ciudades 33). }
\end{aligned}
$$

Y, en significativa autodefinición: “Soy simultáneamente la gran ciudad y la pequeña aldea” ("Homenaje a Abraxas", Homenaje).

Mario Goloboff escribió en el exilio, en su novela Caballos por el fondo de los ojos:

Arguentine. Aryentine. Argentina. Primero es la patria del habla, hay que hacer un idioma desde la raíz. Un lenguaje que para resonar como tug y querer decir “día” sea día desde lo más hondo, con su luz, su viento y sus pájaros desconocidos. Hay que esforzarse para que pronunciar sea sentir... Para que señal y sensación vuelvan al cauce, y decir “día” sea como sentir tug, porque tug no es noche ni oscuridad ni frío, es sol mañana clara cielo grande (26).

\footnotetext{
${ }^{21}$ Algunos ejemplos entre muchos de esas formas de "detonante" textual son: los relatos familiares en Genealogías de Margo Glantz y en El libro de los recuerdos de Ana María Shua; las fotografías en Yiskor de Gloria Gervitz y Animales feroces de Isaac Chocrón; la investigación genealógica en El árbol de la gitana de Alicia Dujovne Ortiz.
} 
En una primera lectura, se trata de la frustración del inmigrante ante un idioma que no le significa nada, no le representa mundo. Creo, sin embargo, que hay en este texto dos deseos: uno, el del personaje que quiere adquirir un lenguaje que aún no tiene; el otro, el del narrador-autor que ya posee el lenguaje donde se dice "día” pero anhela que esa palabra incluya también “tug”, que le sea posible poseer también el lenguaje de ese espacio imaginario para él, perdido para él.

En su poema "Desarraigo", escribe Alberto Szpunberg:

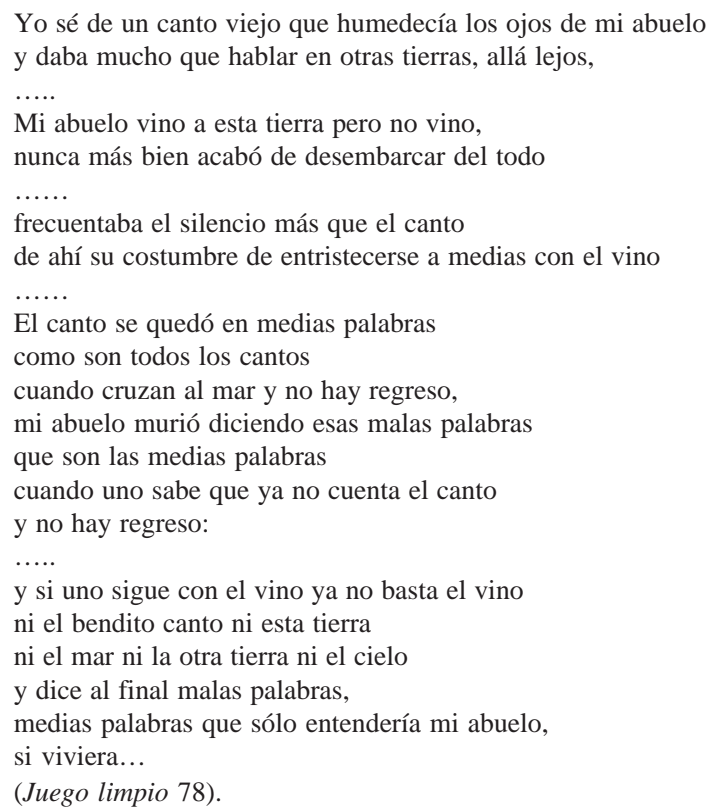

Echar raíces en todas las historias, alcanzar la palabra doble, completar la media palabra con aquélla que sólo entendería el abuelo, incorporar al "maravilloso espacio" de la escritura los dos mundos a los que se pertenece, sería haber salido del Hotel de Inmigrantes y alcanzado la orilla en que el migrante-mestizo no deba renunciar ni a la maleta traída de allá ni a la raíz nutrida en la tierra de acá. 
BiBLIOGRAFÍA

Aizenberg, Edna. The Aleph Weaver: Biblical, Kabbalistic, and Judaic Elements in Borges. Potomac, MD: Scripta Humanística, 1985.

Alazraki, Jaime. Borges and the Kabbalah and Other Essays on His Fiction and Poetry. Cambridge: Cambridge University Press, 1988.

AMILAT (ed.) Judaica Latinoamericana-Estudios Históricos-Sociales. Jerusalén: Magnes I, 1988; II, 1993; III, 1997; IV, en prensa.

Borges, Jorge Luis. “El escritor argentino y la tradición”. Discusión. Buenos Aires: Emecé, 1964. 151-162.

Cornejo-Polar, Antonio. “Tradición migrante e intertextualidad multicultural: el caso de Arguedas”. CELEHIS V-6/7/8 (1996): 45-56. [versión en inglés “The Migrant Condition and Milticultural Intertextuality: The Case of Arguedas”. Journal of Latin American Cultural Studies VII-1 (1998): 29-37].

Darío, Rubén. “Canto a la Argentina” [1910]. Poesías Completas. Madrid: Aguilar, 1961. 905-936.

DiAntonio, Robert y Nora Glickman. Tradition and Innovation-Reflections on Latin American Jewish Writing. Albany: State University of New York Press, 1993.

Encyclopaedia Judaica. Jerusalén: Keter Publishing House, 1971.

Ensayos sobre judaísmo latinoamericano. Actas del V Congreso Internacional de Investigadores sobre Judaísmo Latinoamericano (Buenos Aires, 1989). Buenos Aires: Milá, 1990.

Feierstein, Ricardo. “Judíos latinoamericanos: Una nueva forma del mestizaje”. Cuentos judíos latinoamericanos. Buenos Aires: Amia, 1990. Reproducido en El Gran Libro de América Judía. San Juan: Editorial de la Universidad de Puerto Rico, 1999. 10871089.

Finzi, Patricia, Eliahu Toker y Marcos Faerman. El imaginario judío en la literatura de América Latina-Visión y realidad. Actas del congreso homónimo (São Paulo, 1990). Buenos Aires: Grupo Editorial Shalom, 1992.

Gerchunoff, Alberto. Los gauchos judíos. Buenos Aires: CEAL, 1968.

Glantz, Jacobo. "Visa”. Panorama de la poesía judía contemporánea. [1965]. E. Toker, comp. Buenos Aires: Raíces, 1989. 148.

Glickman, Nora. "Introduction II: The Authors Speak for Themselves”. Tradition and Innovation-Reflections on Latin American Jewish Writing. Robert DiAntonio y Nora Glickman, eds. Albany: State University of New York Press, 1993. 9-31.

Goldberg, Florinda F. “'Carta de naturalización’: Femineidad, judaísmo y universalidad en la poesía de Myriam Moscona”. The Mezuzah at La Malinche's Door: Critical Approaches to Mexican Jewish Literature. Darrell Lockhart, ed. En preparación. "Reseña de El Gran Libro de América Judía”. Reflejos 8 (1999): 145-147.

"The Complex Roses of Jerusalem: The Theme of Israel in Argentinian Jewish Poetry”. Tradition and Innovation-Reflections on Latin American Jewish Writing. Robert DiAntonio y Nora Glickman, eds. Albany: State University of New York Press, 1993. 73-87. 
Goldberg, Isaac. “Jewish Writers in South America”. The Menorah Journal XI-5 (October 1925): 473-483.

Goldemberg, Isaac (ed.). El Gran Libro de América Judía. San Juan: Editorial de la Universidad de Puerto Rico, 1999.

Goloboff, G. Mario. Caballos por el fondo de los ojos. Buenos Aires: Planeta, 1976.

Grumet, Elinor. “The Apprenticeship of Lionel Trilling”. Prooftexts 4 (1984): 153-173.

Karduner, Luis. “Carta abierta a César Tiempo”. Judaica 45 (marzo 1937): 99-104. "Misión de escritor judío en la literatura argentina”. Judaica 16 (octubre 1934): 145149.

King, R., J. Cornell y P. White (eds.). Writing across Worlds. Literature and Migration. Londres: Routledge, 1995.

Kovadloff, Santiago. “En el umbral de la poesía judía latinoamericana”. Panorama de la poesía judía contemporánea-Celebración de la palabra. Eliahu Toker, ed. Buenos Aires: Milá, 1989. 143-145.

"Legitimar la diversidad cultural”. Pluralismo e identidad: Lo judío en la literatura latinoamericana (VV.AA.). Buenos Aires: Milá, 1986. 25-28.

Lévy, Bernard-Henri (1987) “Existe-t-il une littérature juive?”. Le Figaro Magazine 390 (20/6/1987): 12-13.

Liacho, Lázaro. Sónidas desde la pampa y Sonata judía de Nueva York. Buenos Aires: Candelabro, 1969.

Lindstrom, Naomi. Jewish Issues in Argentine Literature-From Gerchunoff to Szichman. Columbia: University of Missouri Press, 1989.

"Las polémicas culturales en las páginas literarias de Judaica". Noaj 12-13 (diciembre 1997): 42-50.

Lockhart, Darrell (ed.). Jewish Writers of Latin America-A Dictionary. Nueva York y Londres: Garland Publiching, 1997.

The Mezuzah at La Malinche's Door: Critical Approaches to Mexican Jewish Literature. En preparación.

Moscona, Myriam. Las visitantes. México, DF: Joaquín Mortiz, 1989.

Muñiz-Huberman, Angelina. "Reseña de El Gran Libro de América Judía”. Latin American Jewish Studies XIX-2 (May 1999): 4-5.

Noaj 3-4. Actas del VEncuentro Internacional de Escritores Judíos en Español y Portugués (Israel, 1989). Jerusalén: Asociación Internacional de Escritores Judíos en Lengua Hispana y Portuguesa (mayo 1989).

Noaj 7-8. “Quinto Centenario: Tierras de expulsión y tierras de promisión”. Actas del congreso homónimo (Israel, 1992). Jerusalén: Asociación Internacional de Escritores Judíos en Lengua Hispana y Portuguesa (diciembre 1992) .

Pecar, Samuel. “El periplo de un escritor judeo-argentino”. Pluralismo e identidad: Lojudío en la literatura latinoamericana (VV.AA.). Buenos Aires: Milá, 1986. 245-250.

Pluralismo e identidad: Lo judío en la literatura latinoamericana (VV.AA.). Buenos Aires: Milá, 1986.

Porzecanski, Teresa. "Debate abierto”. Pluralismo e identidad: Lo judío en la literatura latinoamericana (VV.AA.). Buenos Aires: Milá, 1986. 149-150. 
Resnick, Salomón. “Florecimiento de la cultura judía en América”. Judaica 96 (junio 1941): 241-242.

Rosa, Jaime B. (ed.). 500 años después: Sepharad, las Américas y la nueva cultura israelí. Actas del congreso homónimo (Miami 1992). Valencia: l’Excel.lentíssim Ajuntament de l'Eliana, 1993.

Rozitchner, León. Ser judío. Buenos Aires: Ediciones de la Flor, 1988.

Scliar, Moacyr. Entrevista. Tradition and Innovation-Reflections on Latin American Jewish Writing. Robert DiAntonio y Nora Glickman, eds. Albany: State University of New York Press, 1993. 28-29.

Senkman, Leonardo. La identidad judía en la literatura argentina. Buenos Aires: Pardés, 1983.

“Exilio y literatura judía”. Noaj 2 (julio 1988): 2-3.

Solotaroff, Ted. “American-Jewish Writers: On Edge Once More”. New York Times Book Review (December 18, 1988): 30, 31, 33.

Sosnowski, Saúl. Borges y la cábala-La búsqueda del verbo. Buenos Aires: Hispamérica, 1976.

La orilla inminente. Escritores judíos argentinos. Buenos Aires: Legasa, 1987. et al. "Literatura judeo-latinoamericana". Actas del simposio "Jewish Literature in the Americas: North and South” (Maryland, 1985). Hispamérica 42 (diciembre 1985): 55-97.

Szpunberg, Alberto. Juego limpio. Buenos Aires: Nueva Expresión, 1963.

Tiempo, César. Sabadomingo [1938]. Buenos Aires: Centro Editor de América Latina, 1966.

Toker, Eliahu. Homenaje a Abraxas. Buenos Aires: Nueva Presencia, 1980. Mamá, papá y otras ciudades. Buenos Aires: Contexto, 1988. Un diferente y su diferencia-Vida y obra de Carlos M. Grünberg. Madrid: Mario Muchnik, 1999.

Veblen, Thorstein. “The Intellectual Pre-eminence of Jews in Modern Europe” [1919]. The Portable Veblen. M. Lerner, ed. Nueva York: The Viking Press, 1970. 467-479.

Waldmann, Berta. "O estrangeiro em Clarice Lispector: Uma leitura de A hora da estrela". AMILAT, Judaica Latinoamericana IV (en prensa). 